James K. Rowlett • Gail Winger $\cdot$ Richard B. Carter

Paul L. Wood $\cdot$ James H. Woods

William L. Woolverton

\title{
Reinforcing and discriminative stimulus effects of the neuroactive steroids pregnanolone and Co 8-7071 in rhesus monkeys
}

Received: 17 November 1998 / Final version: 22 January 1999

\begin{abstract}
Rationale and Objectives: The present study was designed to assess possible abuse-related effects of the endogenous neuroactive steroid pregnanolone $(3 \alpha-$ hydroxy-5 $\beta$-pregnan-20-one) and the orally bioavailable, water-soluble neuroactive steroid pro-drug Co 8-7071

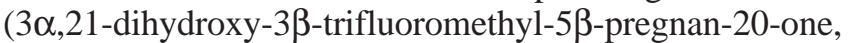
21-hemisuccinate). Methods: Four rhesus monkeys were prepared with chronic intravenous (IV) catheters and trained to press a lever under a ten-response fixed-ratio (FR) schedule of methohexital injection $(0.1 \mathrm{mg} / \mathrm{kg}$ per injection). Three rhesus monkeys were trained to discriminate intragastric infusions of pentobarbital $(10 \mathrm{mg} / \mathrm{kg})$ from saline infusions under a FR5 schedule of stimulusshock termination. Results: At least two doses of pregnanolone $(0.003-0.1 \mathrm{mg} / \mathrm{kg}$ per injection) maintained injections per session above saline levels in the four monkeys tested, whereas Co 8-7071 (0.01-1.0 mg/kg per injection) maintained injections per session above saline levels in two of four monkeys at relatively low levels of injections per session. In rhesus monkeys trained to discriminate pentobarbital, IV pregnanolone injections $(0.1-1.7 \mathrm{mg} / \mathrm{kg}, 5-\mathrm{min}$ presession) dose-dependently reproduced the discriminative stimulus effects of pentobarbital in all monkeys tested. Intravenous administration of Co 8-7071 (1-10 mg/kg, 5-min presession) resulted in a dose-dependent increase to $>80 \%$ pentobarbital-appropriate responding in two of three monkeys tested. Fol-
\end{abstract}

\footnotetext{
J.K. Rowlett · W.L. Woolverton (

Department of Psychiatry and Human Behavior,

University of Mississippi Medical Center,

2500 North State Street, Jackson, MI 39216, USA

Fax: +1-601-984-5899

G. Winger $\cdot$ J.H. Woods

Departments of Pharmacology and Psychology,

University of Michigan, Ann Arbor, Michigan, USA

R.B. Carter · P.L. Wood

CoCensys, Inc., Irvine, California, USA

Present address:

J.K. Rowlett, Harvard Medical School,

New England Regional Primate Research Center,

Southborough, Massachusetts, USA
}

lowing intragastric infusions of Co 8-7071 (1.0-30 $\mathrm{mg} / \mathrm{kg}$ ), $\geq 80 \%$ pentobarbital-appropriate responding occurred in one out of three monkeys at $10 \mathrm{mg} / \mathrm{kg}$ when administered $60 \mathrm{~min}$ before the session. When administered $120 \mathrm{~min}$ before the session, however, $10-30 \mathrm{mg} / \mathrm{kg}$ Co $8-7071$ reproduced the discriminative stimulus effects of pentobarbital in each of the three monkeys tested. Conclusions: These data demonstrate barbiturate-like abuse-related effects that differed between two pregnane steroids. Whereas pregnanolone functioned as a reinforcer, suggesting that this compound has abuse potential, Co 8-7071 did not, despite having pentobarbital-like discriminative effects.

Key words Neuroactive steroid B Barbiturate .

Self-administration - Discriminative stimulus effects .

Rhesus monkey

\section{Introduction}

Converging evidence indicates that certain pregnane steroids have functional effects similar to other allosteric $\gamma$ aminobutyric acid (GABA) modulators (e.g., barbiturates, benzodiazepines; see Gee et al. 1995; Wieland et al. 1995). In this regard, endogenous pregnane steroids, such as pregnanolone ( $3 \alpha$-hydroxy- $5 \beta$-pregnan-20-one, Fig. 1), and synthetic neuroactive steroids, such as ganaxolone, produce behavioral effects in rodents consistent with anxiolytic, anticonvulsant, and motoric impairing properties (Carter et al. 1997; Edgar et al. 1997; Gasior et al. 1997). In vitro evidence indicates that certain neuroactive steroids, rather than acting at a genomic site, exert their actions at a recognition site on the $\mathrm{GABA}_{\mathrm{A}}$ receptor/ $\mathrm{Cl}^{-}$channel complex (GRC) that is distinct from either the barbiturate or benzodiazepine site (for review, see Gee et al. 1995). Collectively, these observations raise the possibility that neuroactive steroids may be clinically useful alternatives to barbiturates and benzodiazepines as sedatives, anxiolytics, hypnotics, and anticonvulsants. 


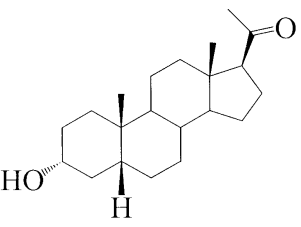

Pregnanolone

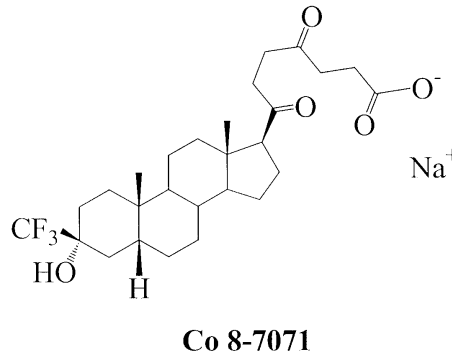

Fig. 1 Structure of pregnanolone ( $3 \alpha$-hydroxy-5 $\beta$-pregnan-20-

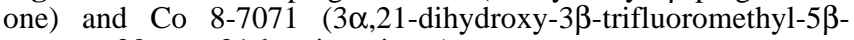
pregnan-20-one, 21-hemisuccinate)

The clinical use of benzodiazepines and barbiturates has been constrained by concerns over the potential for abuse and dependence (Woods and Winger 1995; Griffiths and Weerts 1997), particularly among the elderly and among individuals who are long-term or polydrug abusers (Griffiths and Weerts 1997). Because of the therapeutic benefit of allosteric GABA modulators, development of such compounds with reduced abuse liability is an important area of pharmaceutical research. Although the potential clinical utility of neuroactive steroids seems clear, very little is known with regards to the potential of these compounds for abuse and dependence. Information of this type may be gained from intravenous (IV) selfadministration studies in animals, which are commonly used to study the reinforcing effects and to predict the abuse potential of drugs (Schuster and Thompson 1969; Johanson and Balster 1978). Barbiturates and benzodiazepines have been shown to maintain responding above vehicle levels in IV self-administration procedures, consistent with the documented liability for abuse and dependence exhibited by these compounds (Griffiths et al. 1981, 1991; Bergman and Johanson 1985; Nader et al. 1991). At present, the ability of neuroactive steroids to maintain responding in a manner consistent with reinforcing effects has not been evaluated.

Recent studies have assessed the effects of neuroactive steroids in drug discrimination procedures, which are considered to provide information relevant for understanding the subjective effects of drugs in people (Holtzman 1990). Initial results have indicated that certain neuroactive steroids share discriminative stimulus effects with a variety of positive allosteric modulators of GABA (Ator et al. 1993; Deutsch and Mastropaolo 1993; Vanover 1997). In this regard, Ator et al. (1993) demonstrated that in rats trained to discriminate pentobarbital from saline, the endogenous neuroactive steroids $3 \alpha$, 21-dihydroxy-5 $\alpha$-pregnan-20-one (allotetrahydrodeoxycorticosterone, THDOC) and $3 \alpha$-hydroxy-5 $\alpha$-pregnan-20-one (allopregnanolone) engendered full drug-appropriate responding, indicating that these neuroactive steroids share at least some stimulus effects with a barbiturate.

The present study was designed to assess possible reinforcing effects and barbiturate-like discriminative stimulus effects of both an endogenous and a synthetic neuroactive steroid. The endogenous neuractive steroid chosen was pregnanolone whereas the synthetic steroid chosen was the orally bioavailable, water-soluble neuro-

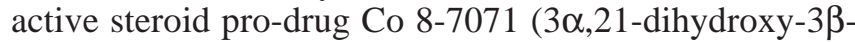
trifluoromethyl-5 $\beta$-pregnan-20-one, 21-hemisuccinate). Co 8-7071 is a recently developed pro-drug that may be biotransformed in vivo by carboxylesterase to the preg-

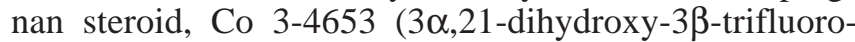
methyl-5 $\beta$-pregnan-20-one), which in preliminary studies has been shown to be a potent allosteric modulator of the GRC in vitro (R. B. Carter, P. L. Wood, unpublished observations). The present study assessed reinforcing and discriminative stimulus effects of these neuroactive steroids in monkeys trained to self-administer methohexital or in monkeys trained to discriminate pentobarbital (cf. Nader et al. 1991), in order to assess the similarity of abuse-related effects of these neuroactive steroids to prototypic barbiturates.

\section{Materials and methods}

Intravenous self-administration

Subjects

The subjects were four rhesus monkeys (Macaca mulatta; one female identified as LI, three males identified as CH852, 3578 and 3577 ) weighing between 5.0 and $9.6 \mathrm{~kg}$ at the beginning of the experiment. Each of the monkeys had a previous history of IV methohexital administration. Animal maintenance and research were conducted in accordance with "Principles of laboratory animal care" (NIH publication No. 85-23, revised 1985), and protocols were approved by the Institutional Animal Care and Use Committee of the University of Michigan.

\section{Surgery and apparatus}

The monkeys were individually housed in stainless steel cages measuring $83.3 \times 76.2 \times 91.4 \mathrm{~cm}$. They were prepared surgically with indwelling silicone rubber catheters (Mox-Med. Inc., Portage, Wisc., USA) using $10 \mathrm{mg} / \mathrm{kg}$ IM ketamine and $2 \mathrm{mg} / \mathrm{kg} \mathrm{IM}$ xylazine as anesthetics. Cathethers were implanted in jugular (internal or external), femoral or brachial veins. The catheter passed subcutaneously from the site of the incision to the mid-scapular region, where it exited the monkey and continued through a hollow restraining arm to the outside rear of the cage. The catheters were fed through roller infusion pumps (Watson-Marlow Co., Model MHRK 55, Falmouth, UK). The monkeys wore a tubular stainless-steel harness (Robert Mackal, Chicago, Ill., USA) that fastened to the restraining arm, and Teflon jackets (Alice King Chatam Medical Arts, Los Angeles, Calif., USA) to protect the catheter. Experimental control was provided by an IBM PS/2 computer programmed with Med-PC software (Med-Associates, Fairfield, Vt., USA) and located in an adjacent room.

\section{Procedure}

Reinforcing effects were evaluated in a substitution procedure with methohexital injections serving as the baseline condition. Each monkey was given access to methohexital, saline, or test compounds available IV as a consequence of responses on one of two levers located on the side of the animal's cage. Only one lever was active; responses on the other lever had no consequence and were not recorded. A red stimulus light was illuminated over the functional lever during each of two daily 130-min sessions of drug access. In the presence of this light, ten responses (FR10) on the 
lever resulted in the IV delivery of a 5-s, 1.0-ml injection of saline solution, sodium methohexital $(0.1 \mathrm{mg} / \mathrm{kg}$ per injection) or a test compound. Following each injection, the light was extinguished for $10 \mathrm{~s}$ (time-out); during this time-out responses had no programmed consequences. No limit was placed on the number of injections the animals could self-administer.

Two sessions were scheduled each day. One session ran from approximately 10:00 a.m. to 12:10 p.m., whereas the other session ran from approximately 4:00 p.m. to 6:10 p.m. On approximately half of the baseline sessions, the monkeys were exposed to response-contingent saline. Methohexital and saline were available in a non-systematic order: monkeys could get methohexital on one session and saline on the other, but also could get methohexital on both sessions or saline on both sessions. All animals showed clear and consistent differential responses to saline and methohexital before test compounds were substituted. For test sessions, a dose of test compound was made available for one session only, either in the morning or afternoon session. Dose variations were made by changes in the concentration of the drug. The doses of pregnanolone available for injection were $0.003,0.01,0.03$ and $0.1 \mathrm{mg} / \mathrm{kg}$ per injection. The doses of Co 8-7071 available for injection were $0.01,0.03,0.1,0.3$ and $1.0 \mathrm{mg} / \mathrm{kg}$ per injection; one monkey was tested at $1.8 \mathrm{mg} / \mathrm{kg}$ per injection. Each dose of pregnanolone or Co 8-7071 was determined either two or three times. Dose order selection was made randomly.

Multiple determinations of responding during saline and methohexital availability were made over the course of the experiment. To determine whether a drug functioned as a reinforcer, the range of injections per session after saline availability during the course of testing a particular drug was compared to the average injections per session of test compound for individual monkeys. Injections per session after a given dose of neuroactive steroid were considered reinforcing doses in individual monkeys if the injections per session fell above the range of saline injections per session.

\section{Drugs}

Sodium methohexital was donated by Eli Lilly and Co. (Indianapolis, Ind., USA) and dissolved in sterile water. Pregnanolone was synthesized by CoCensys, Inc. (Irvine, Calif., USA) and suspended in hydroxypropyl- $\beta$-cyclodextrin $(50 \%, \mathrm{w} / \mathrm{v}$; mixed in saline). Co 8-7071 was synthesized by CoCensys, Inc. and dissolved in sterile water. The pregnanolone suspensions and Co 8-7071 solutions were sterilized by filtration $(0.2 \mu \mathrm{m}$, Gelman Sciences, Ann Arbor, Mich., USA).

\section{Drug discrimination}

\section{Subjects}

The subjects were three male rhesus monkeys weighing between 6.0 and $11.5 \mathrm{~kg}$ at the beginning of the experiment. One monkey (8814) had extensive experience with the present drug discrimination procedure, the other monkeys (REf3, AQ63) had been tested previously with benzodiazepines only (Rowlett and Woolverton 1998). All monkeys were housed individually in stainless-steel cages in which water was continuously available and fed 120-150 g monkey chow after each session, supplemented with fresh fruit and vegetables. In addition, the monkeys were given a chewable vitamin tablet, formulated for children, 3 days per week. Animal maintenance and research were conducted in accordance with "Principles of laboratory animal care" (NIH publication No. 85-23, revised 1985), and protocols were approved by the Institutional Animal Care and Use Committee of the University of Mississippi Medical Center.

\section{Apparatus}

During experimental sessions each monkey was seated in a restraining chair (Plas Labs, Lansing, Mich., USA; or Primate Products, Redwood City, Calif., USA) and placed in one of two cubi- cles, depending on the type of chair used (for Plas Labs chairs: $175 \mathrm{~cm}$ high $\times 85 \mathrm{~cm}$ wide $\times 65 \mathrm{~cm}$ deep, custom-made with wood covered by epoxy coating; for Primate Products chairs: $116 \mathrm{~cm}$ high $\times 85 \mathrm{~cm}$ wide $\times 67.5 \mathrm{~cm}$ deep, BRS/LVE, Laurel, Md., USA). Both cubicle types contained two response levers mounted above the floor $(100 \mathrm{~cm}$ for the first cubicle described, $72.5 \mathrm{~cm}$ above the floor for the second), four white stimulus lights above each lever, and a 40-W white house light was mounted on the ceiling. The monkey's feet were placed into shoes, the bottoms of which were fitted with brass plates that could deliver electric shocks. Programming and recording of experimental events were accomplished using Macintosh II computers and associated interfaces located in an adjacent room.

\section{Discrimination training}

The three monkeys had been trained previously to discriminate pentobarbital from saline in a two-lever, discrete-trials shock avoidance procedure. During training sessions, the monkeys were placed in the chairs, administered an intragastric (IG) infusion (via nasogastric tube) of saline or $10 \mathrm{mg} / \mathrm{kg}$ pentobarbital $(0.25 \mathrm{ml} / \mathrm{kg})$, then returned to their home cages. Fifty-five minutes later, the monkeys were seated again in the chair and placed in the chamber. After $5 \mathrm{~min}$, the house light and lever lights were illuminated (trial) and five responses (fixed ratio 5, FR5) on one lever (correct lever) avoided electric shock (avoidance response) and extinguished the lights. If a response requirement on the correct lever was not made within $10 \mathrm{~s}$ of onset of the lights, an electric shock $(250 \mathrm{~ms}$ duration, $5.0 \mathrm{~mA}$ intensity) was delivered. If a response requirement on the correct lever was made within $4 \mathrm{~s}$ after the first shock (escape response), the trial was terminated. Otherwise, a second shock was delivered and the trial ended. Two consecutive trials in which a monkey failed to make an avoidance or escape response ended the session. Trials were separated by 30 -s time-outs in which all lights were off and responding had no programmed consequences. The sessions lasted 30 trials or $20 \mathrm{~min}$, whichever came first. The correct lever was determined by the infusion that was administered before the session. For two monkeys, the left lever was correct after drug infusion and the right lever was correct after saline infusions. This condition was reversed for the other monkey. The sequence of daily (5 days/week) sessions was SDDSS, DSSDD (S: saline presession, D: drug presession).

\section{Testing}

When $90 \%$ of responses during the first trial and at least $90 \%$ of responses in all trials were completed on the correct lever for at least seven of eight sessions, test sessions were added to this sequence. The test sessions occurred on days 3 and 5 of the 5-day sequence (i.e., SDTST, DSTDT, where T denotes a test session). Test sessions were identical to training sessions except that completion of a FR5 on either lever avoided or escaped shock delivery. In the event that either criterion for stimulus control was not met during the training sessions, the training sequence continued without test sessions until the criteria were met again.

In test sessions, a dose-response function for pentobarbital $(3.0-17 \mathrm{mg} / \mathrm{kg}$ ) given IG and 60 -min presession was determined first. These tests were followed by determinations of the effects of Co 8-7071 (1.0-30 mg/kg), first given IG and $60 \mathrm{~min}$ presession, then based on these initial results, given 120 min presession. Due to its low bioavailability, pregnanolone was administered IV, which also facilitated comparisons with the IV self-administration data. In order to make similar comparisons, Co 8-7071 and pentobarbital were also tested after IV injections. For IV tests, monkeys were seated in chairs and a 25-gauge needle was inserted in the saphenous vein (injections were alternated left and right calf). Pentobarbital (1.0-10 mg/kg IV), pregnanolone $(0.1-3.0 \mathrm{mg} / \mathrm{kg}$, IV), or Co 8-7071 (0.3-10 mg/kg, IV) was administered either 15 (pentobarbital) or 5 (pregnanolone, Co 8-7071) min prior to the beginning of the session. All doses were tested in a non-systematic order. 
Drugs

Pentobarbital (Nembutal, $50 \mathrm{mg} / \mathrm{ml}$, Abbott Laboratories, Chicago, Ill., USA) was diluted with $0.9 \%$ saline to a final concentration that enabled injection in a constant volume of $0.25 \mathrm{ml} / \mathrm{kg}$, except for the $17 \mathrm{mg} / \mathrm{kg}$ dose, which was not diluted. Pregnanolone and Co 8-7071 were synthesized by CoCensys, Inc. Pregnanolone was suspended in a $40 \%(\mathrm{w} / \mathrm{v})$ solution of hydroxypropyl- $\beta$-cyclodextrin (mixed with saline) and Co 8-7071 was dissolved in water. For IV injections, the drug suspensions or solutions were filtersterilized (0.2 $\mu \mathrm{m}$, Nalge Co., Rochester, N.Y., USA) and injected in a volume of $0.25 \mathrm{ml} / \mathrm{kg}$. For IG infusions, pentobarbital and Co 8-7071 were administered by way of a nasogastric tube which was dipped in mineral oil, followed by a flush with $2 \mathrm{ml}$ saline to clear the tube. Pentobarbital during training sessions and test solutions/suspensions were prepared immediately before the session in which they were available.

\section{Data analysis}

The percentage of the total trials completed on the pentobarbitalappropriate lever and the response rate (mean responses/s before completion of a trial, averaged across trials and including trials in which no responding occurred) were calculated for test sessions for each subject. For individual monkeys, full drug-appropriate responding was concluded if $80 \%$ or more of the trials were completed on the drug-appropriate lever. Lack of drug-appropriate responding was concluded if responding on the drug trials was $20 \%$ or less of total trials. Between 20 and $80 \%$ was considered partial drug-appropriate responding.

\section{Results}

\section{Self-administration}

In the four monkeys, methohexital $(0.1 \mathrm{mg} / \mathrm{kg}$ per injection) maintained injections per session that were higher than those maintained under saline availability (Fig. 2, compare points above " $\mathrm{M}$ " to vertical bars in the leftmost "saline" panel). The number of determinations of injections per session maintained by methohexital and saline ranged from six to ten across the monkeys for each determination of test compound.

Pregnanolone maintained responding above the range of injections per session maintained by saline in the four monkeys (Fig. 2). Responding maintained by pregnanolone was dose-dependent, with the lowest dose $(0.003$ $\mathrm{mg} / \mathrm{kg}$ per injection) maintaining from 14 to 54 injections per session and peak doses (generally 0.01$0.1 \mathrm{mg} / \mathrm{kg}$ per injection, depending on the monkey) maintaining from 46 to 170 injections per session. Except for monkey 3576, the dose-response functions were biphasic, conforming to an inverted U-shaped function (Fig. 2). Except for monkey L1, peak responding maintained by pregnanolone was below the methohexital baseline.

Co 8-7071 maintained low levels of responding, with the majority of injections per session falling in the range observed during saline availability (Fig. 2). The exceptions were monkeys LI and CH852, in which one or two doses maintained responding above saline levels, but only by one to five injections per session above the upper limit of the range for saline.

\section{Drug discrimination}

Pentobarbital, administered IG, 60 min presession, produced full and dose-dependent drug-appropriate responding in all monkeys tested (Fig. 3, top left panel). That is, as the dose of pentobarbital was increased, percent drug-appropriate trials increased from saline-like levels $(0 \%)$ to $100 \%$ drug-appropriate trials at 5.6 $\mathrm{mg} / \mathrm{kg}$ and above. Pentobarbital also produced a dosedependent decrease in response rate. When administered IV and $15 \mathrm{~min}$ before the session, pentobarbital produced full and dose-dependent drug-appropriate re-

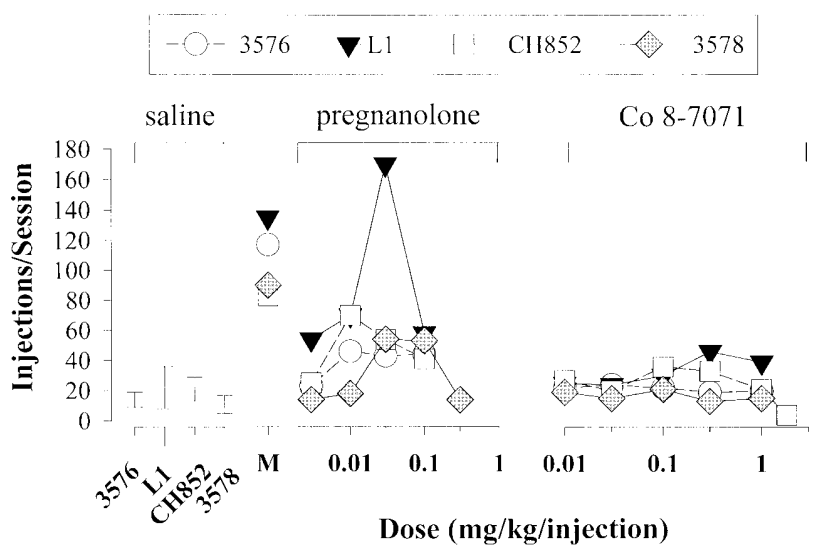

Fig. 2 Intravenous self-administration tests for pregnanolone and Co $8-7071$ by four rhesus monkeys. Data are from individual subjects, identified on the leftmost panel (under saline) and as individual symbols $(\bigcirc 3576, \boldsymbol{\nabla} 1, \square \mathrm{CH} 852, \bigcirc 3578)$. Points above $M$ represent the average injections per session during six to ten sessions of methohexital $(0.1 \mathrm{mg} / \mathrm{kg}$ per injection) availability. Vertical bars in the left saline panel represent the range of injections per session during six to ten sessions of saline availability. Data for pregnanolone and Co 8-7071 represent the average of two or three determinations

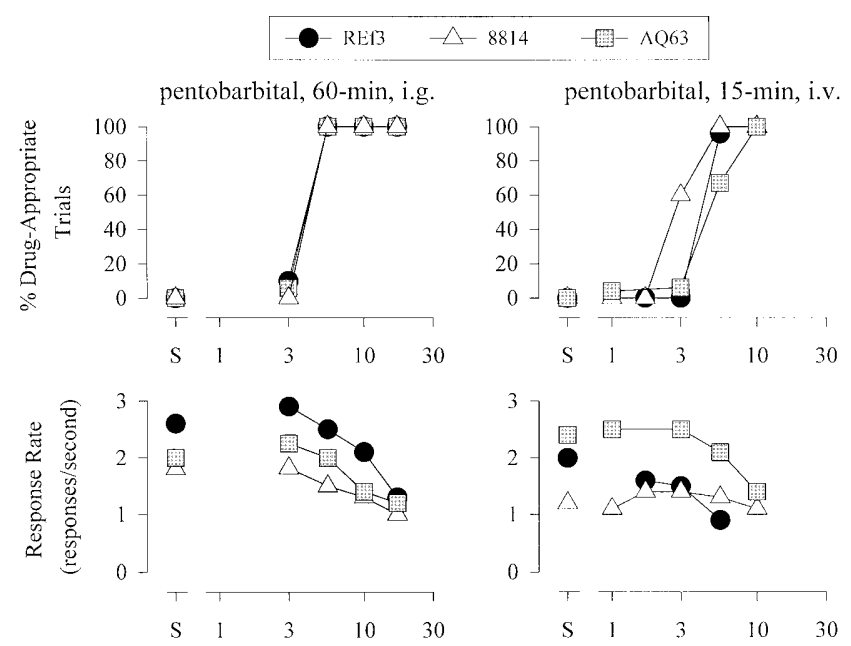

Fig. 3 Discriminative stimulus effects of pentobarbital, administered either IG 60 min presession or IV, 15-min presession, in pentobarbital-trained rhesus monkeys. Each symbol represents an individual monkey ( REf3, $\triangle 8814$, 圈 AQ63). Points above $S$ represent results from tests with saline infusions 
sponding in all monkeys tested, with greater than $80 \%$ drug-appropriate responding at either 5.6 or $10 \mathrm{mg} / \mathrm{kg}$ (Fig. 3, right top panel). After IV administration, pentobarbital produced a dose-dependent decrease in response rate for monkeys REf3 and AQ63 that was maximal at either 5.6 or $10 \mathrm{mg} / \mathrm{kg}$, respectively. Response rate did not change appreciably for monkey 8814 at any dose of pentobarbital.

Pregnanolone engendered dose-dependent increases in pentobarbital-appropriate responding up to and greater than $80 \%$ in the three monkeys tested (Fig. 4, top left panel). The only marked suppression of response rate was observed for REf3 at $1.7 \mathrm{mg} / \mathrm{kg}$ (Fig. 4, bottom left panel). For the other monkeys, however, slight or no systematic trends for alterations in response rate were observed after pregnanolone administration. Co 8-7071, after IV administration, also occasioned a dose-dependent increase in pentobarbital-appropriate responding (Fig. 4, top right panel). Drug-appropriate responding was $>80 \%$ at $10 \mathrm{mg} / \mathrm{kg}$ Co $8-7071$ for monkeys REf3 and AQ63. However, for monkey 8814, the maximum percent drugappropriate trials engendered by Co 8-7071 was $42 \%$ at $5.6 \mathrm{mg} / \mathrm{kg}$. When tested at $10 \mathrm{mg} / \mathrm{kg}$ Co 8-7071, this monkey did not respond (open triangle above "10", bottom right panel of Fig. 4). Dose-dependent decreases in response rate were apparent for monkeys REf3 and AQ63, with maximum decreases observed at $10 \mathrm{mg} / \mathrm{kg}$.

Co 8-7071, administered IG at the 60-min presession time, occasioned $>80 \%$ pentobarbital-appropriate responding for monkey AQ63 only (Fig. 5, top left panel). For monkeys REf3 and 8814, IG Co 8-7071 at $60 \mathrm{~min}$ presession occasioned a maximum of $72 \%$ and $10 \%$ drug-appropriate trials, respectively. Response rate was suppressed in a dose-dependent fashion by IG Co 8-7071

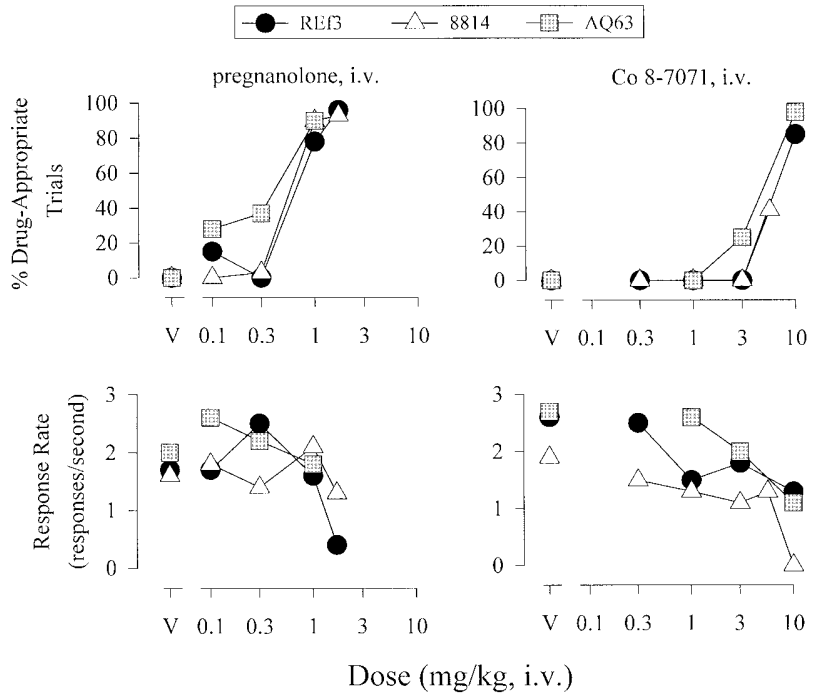

Fig. 4 Discriminative stimulus effects of pregnanolone and Co 87071 , administered IV and 5 min presession, in pentobarbitaltrained rhesus monkeys. Each symbol represents an individual monkey ( REf3, $\triangle 8814$, 圆 AQ63). Points above $V$ represent results from tests with pregnanolone vehicle (40\% hydroxypropyl- $\beta$ cyclodextrin) or the Co 8-7071 vehicle (saline) at 60 min presession in monkey AQ63 only. When the presession time was increased to $120 \mathrm{~min}$, more orderly percent drug-appropriate trials and response rate suppression was observed for the monkeys tested relative to the 60-min presession time (Fig. 5). Pentobarbital-appropriate responding reaching $80 \%$ or greater was observed at $10 \mathrm{mg} / \mathrm{kg}$ Co 8-7071 for monkeys REf3 and AQ63; $100 \%$ pentobarbital-appropriate responding was observed at $30 \mathrm{mg} / \mathrm{kg}$ for monkeys 8814 and REf3. Response rate after Co 8-7071, IG and 120 min presession, was decreased in a dose-dependent manner in the three monkeys, with maximum suppression occurring at 17 or $30 \mathrm{mg} / \mathrm{kg}$ Co 8-7071.

\section{Observable behavioral effects}

Animals in both self-administration and drug discrimination studies were frequently monitored for behavioral and physiological signs of depressant-associated effects. In the drug discrimination studies, IV pregnanolone $(1.0 \mathrm{mg} / \mathrm{kg})$ produced signs of ataxia (i.e., unable to grasp a 1-g banana-flavored pellet or slice of apple), excessive salivation and sedation (i.e., eyes closed, but aroused after experimenter clapped hands). At the dose of $1.7 \mathrm{mg} / \mathrm{kg}$, the two monkeys tested were noted as having stage III surgical anesthesia by an attending veterinarian. This anesthesia began immediately after injection and lasted approximately $5 \mathrm{~min}$. The monkeys recovered abruptly, with signs of ataxia and sedation. Observations performed immediately after the session revealed no evidence of any drug effect.

Although not reliably self-administered above saline levels in two of four subjects, the highest dose of Co 8$7071(1.0 \mathrm{mg} / \mathrm{kg}$ per injection) resulted in total administered doses of $18-32 \mathrm{mg} / \mathrm{kg}$. Animals showed evidence

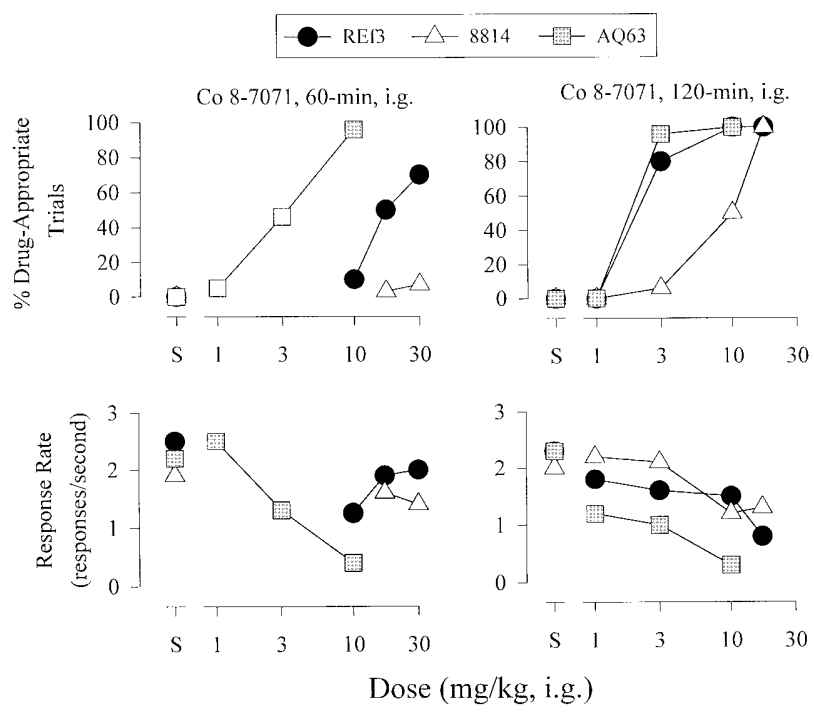

Fig. 5 Discriminative stimulus effects of Co 8-7071, administered IG either 60 or 120 min presession, in pentobarbital-trained rhesus monkeys ( REf3, $\triangle$ 8814, 圈 AQ63). For other details, see Fig. 4 
of sedation (eyes closed, lying down in cage) after sessions in which $1.0 \mathrm{mg} / \mathrm{kg}$ per injection $(18-32 \mathrm{mg} / \mathrm{kg})$ of Co 8-7071 was available. After IV and IG administration of Co 8-7071 in the drug discrimination studies, at doses of $10 \mathrm{mg} / \mathrm{kg}$ and above, all animals showed evidence of ataxia (unable to grasp a 1-g banana-flavored pellet or slice of apple), excessive salivation and sedation (eyes closed, but aroused after experimenter clapped hands). The onset of these effects was immediate after IV injection, whereas these effects were not observed until 60-120 min after IG administration. Ataxia-like effects, salivation and sedation were observed approximately $9 \mathrm{~h}$ after IV or IG administration of Co 8-7071 at $10 \mathrm{mg} / \mathrm{kg}$. Based on this latter observation, the possibility that Co 8-7071 had effects lasting $24 \mathrm{~h}$ after administration was assessed by examining performance on next-day saline training sessions. Across all animals, all doses of Co 87071 were available in a test session followed by a saline training session. In no case, even following administration of the higher doses of Co 8-7071, was saline training performance impaired $24 \mathrm{~h}$ after Co 8-7071 injection. Likewise, signs of ataxia and sedation were not evident $24 \mathrm{~h}$ after Co 8-7071 administration.

\section{Discussion}

The endogenous neuroactive steroid pregnanolone maintained behavior above saline levels in all monkeys tested, indicating that this steroid functioned as a positive reinforcer. To our knowledge, this is the first report demonstrating reinforcing effects of this class of compounds, raising the possibility that some neuroactive steroids may have potential for abuse in humans. In contrast to the results with pregnanolone, however, the synthetic neuroactive steroid pro-drug Co 8-7071 did not maintain appreciable amounts of responding above saline levels in the four monkeys tested, suggesting that this pro-drug may possess low potential for abuse. Collectively, these results indicate that the recently developed pro-drugs for neuroactive steroids may offer the significant advantage, in addition to water solubility and increased oral bioavailability, of reduced abuse potential in comparison to the endogenous neuroactive steroids.

Both pregnanolone and Co 8-7071, after IV administration, engendered dose-dependent increases in drug-appropriate responding in monkeys trained to discriminate pentobarbital from saline. Co 8-7071 was equipotent with pentobarbital, and both compounds were approximately 10 -fold less potent than pregnanolone. The finding of drug-appropriate responding engendered by both neuroactive steroids is consistent with previous data in pentobarbital-trained rats, in which the endogenous neuroactive steroids THDOC and allopregnanolone produced dose-dependent increases in drug-appropriate responding (Ator et al. 1993). Progesterone, the steroid precursor to pregnane neuroactive steroids, also exhibited discriminative stimulus effects similar to pentobarbital in rats (Heinsbroek et al. 1987). In addition to results with pentobarbital as the training drug, certain neuroactive steroids have also been shown to engender full drugappropriate responding in subjects trained to discriminate other GRC positive modulators. In this regard, Ator et al. (1993) demonstrated that allopregnanolone and THDOC occasioned full drug-appropriate responding in rats trained to discriminate ethanol or diazepam, but not lorazepam. Allopregnanolone and THDOC also produced full and dose-dependent drug-appropriate responding in cynomolgus monkeys trained to discriminate ethanol (Grant et al. 1996, 1997), whereas THDOC produced full drug-appropriate responding in rats trained to discriminate the benzodiazepine midazolam (Deutsch and Mastropaolo 1993). Recently, Vanover (1997) demonstrated that pentobarbital and diazepam fully reproduced the discriminative stimulus effects of pregnanolone in rats. Taken together, these results suggest that neuroactive steroids that act as positive GRC modulators share some discriminative stimulus effects with pentobarbital, as well as other GRC modulators, in both rats and monkeys.

Co 8-7071 was active and approximately equipotent IG as compared with the IV route; the onset of action appeared to occur between 60 and 120 min after oral administration. Consistent with these observations, preliminary pharmacokinetic experiments in rhesus monkeys have revealed that plasma levels of the $21-\mathrm{OH}$ metabolite of Co 8-7071 (Co 3-4653), following IG administration of $10 \mathrm{mg} / \mathrm{kg}$ of the pro-drug, reached asymptotic levels $120 \mathrm{~min}$ after oral administration and remained relatively high for up to $12 \mathrm{~h}$ (RB Carter, unpublished observations). It should be noted, however, that the role of active metabolites in the pharmacological activity of Co 8-7071 remains to be determined. Furthermore, discriminative stimulus effects of Co 8-7071 were apparent 5 min after IV administration, suggesting that either the parent drug itself is active or that hydrolysis to active metabolites occurs rapidly in blood but slowly via the GI system. Interestingly, pentobarbital itself was effective and equipotent when given IG as compared to IV Pentobarbital is not thought to have active metabolites, suggesting that this pattern of effects can occur with a parent drug.

Previous studies have shown that pentobarbital and methohexital share both reinforcing and discriminative stimulus effects under conditions similar to those used in the present study (Winger and Herling 1982; Nader et al. 1991). The fact that Co 8-7071 had discriminative stimulus effects in common with pentobarbital but was not self-administered raises some interesting questions. One interpretation of these data is that the doses of Co 8-7071 tested in the self-administration study were not high enough to maintain responding. When the dose of Co 8 7071 in the self-administration studies was expressed as total drug per kg body weight (i.e., total injections taken multiplied by dose), between 18 and $32 \mathrm{mg} / \mathrm{kg}$ Co 8 7071 was self-administered at the higher doses. Based on total $\mathrm{mg} / \mathrm{kg}$, the dose levels clearly were comparable in these animals to the doses injected IV in the discrimina- 
tion studies. In addition to dose, several properties of a drug are generally thought to account for their failure to maintain IV self-administration in this preparation. Drugs have either negative effects (thought to be the case for kappa opioid agonists and perhaps antipsychotic compounds) or have no positive effects, or have slow onsets of action, even following IV administration (e.g., CGS 19755 and LAAM, Winger, unpublished observations). None of these aspects seems to apply to the situation with Co 8-7071. The interoceptive effects of this compound were shown to be like those of pentobarbital, a drug with known abuse liability that is self-administered by non-human primates (Griffiths et al. 1981, 1991; Nader et al. 1991). It was also shown to have a rapid onset of action when given IV in the drug discrimination paradigm, and by direct observation in the selfadministration procedure. This drug therefore presents an unusual profile of action in abuse liability tests. A similar profile was suggested for brotizolam (Nader et al. 1991), although the onset of brotizolam's actions was not as clearly defined in that study as was that of Co 8-7071 in this study.

One possible explanation is a relatively greater ratio of sedative to discriminative or reinforcing stimulus effects and/or a longer duration of sedative effects for drugs with this pattern of action. The data indicate that, following IV administration, pentobarbital had discriminative stimulus effects at doses that produced only modest suppression of rates of responding. This was true as well for Co 8-7071 for two of the monkeys, although the third monkey showed profound suppression of rates of responding at doses below those that produced only a modest amount of pentobarbital-appropriate responding. In the behavioral observations, pregnanolone had a very short duration of action (approximately $5 \mathrm{~min}$ ) and Co 87071 had quite a long duration of action (between 9 and $24 \mathrm{~h}$ ). Presumably the duration of action of pentobarbital would be greater than that of pregnanolone and less than that of Co 8-7071. It is therefore possible that the inability of Co 8-7071 to maintain self-administration was due to prolonged sedative effects that impacted on the ability of the animals to continue to respond and receive drug. An evaluation of the reinforcing and discriminative stimulus effects of a long-acting barbiturate such as phenobarbital, under conditions similar to those used here, might help clarify the role of duration of action on these preclinical measures of abuse potential.

Recently, Ator and Griffiths (1997) noted that categorization of sedative-anxiolytics in terms of their ability to reproduce the stimulus effects of the benzodiazepine lorazepam bears little relationship to the ability of these drugs to maintain responding in self-administration procedures. These authors further suggest that drug discrimination and self-administration procedures, although both presumably dependent on stimulus effects of drugs, assess different aspects of the stimulus effects of the same drug. The results of the present study, pharmacokinetics notwithstanding, corroborate these observations since Co 8-7071 clearly shared discriminative stimulus effects with pentobarbital but lacked the reinforcing stimulus effects observed with methohexital.

Collectively, these results raise the possibility that certain neuroactive steroids may exhibit a profile of reinforcing and discriminative stimulus effects that share characteristics with both barbiturates and benzodiazepines. This possibility should be approached with some caution, however, until other neuroactive steroids are tested in drug discrimination and self-administration procedures in comparison with barbiturates and benzodiazepines. Nonetheless, these data support further exploration of neuroactive steroids as clinically therapeutic agents with the potential for reduced abuse liability. Specifically, the neuroactive steroid pro-drug Co 8-7071 demonstrates a behavioral profile consistent with a limited potential for abuse in humans.

Acknowledgements We thank Dr. Donna Platt for comments on an earlier version of this manuscript. We thank Debbie Huntzinger, Elaine Phillips, Joe Richman, Jerry Weems and Brenda Winger for providing technical assistance. This research was supported by NIDA grants DA09139, DA09161, CoCensys, Inc., and the College on Problems of Drug Dependence. J. K. R. was supported by NIDA grant DA11792 during a portion of this study.

\section{References}

Ator NA, Griffiths RR (1997) Selectivity in the generalization profile in baboons trained to discriminate lorazepam: benzodiazepines, barbiturates and other sedative/anxiolytics. J Pharmacol Exp Ther 282:1442-1457

Ator NA, Grant KA, Purdy RH, Paul SM, Griffiths RR (1993) Drug discrimination analysis of endogenous neuroactive steroids in rats. Eur J Pharmacol 241:237-243

Bergman J, Johanson CE (1985) The reinforcing properties of diazepam under several conditions in the rhesus monkey. Psychopharmacology 86:108-113

Carter RB, Wood PL, Wieland S, Hawkinson JE, Belelli D, Lambert JJ, White HS, Wolf HH, Mirsadeghi S, Tahir H, Bolger MB, Lan NC, Gee KW (1997) Characterization of the anticonvulsant properties of ganaxolone (CCD 1042; $2 \alpha$-hydroxy, $3 \beta$ methyl-5 $\alpha$-pregnan-20-one), a selective high-affinity steroid modulator of the $\mathrm{GABA}_{\mathrm{A}}$ receptor. J Pharmacol Exp Ther 280:1284-1295

Deutsch SI, Mastopaolo J (1993) Discriminative stimulus properties of midazolam are shared by a GABA-receptor positive steroid. Pharmacol Biochem Behav 46:963-965

Edgar DM, Seidel WF, Gee KW, Lan NC, Field G, Xia H, Hawkinson JE, Wieland S, Carter RB, Wood PL (1997) CCD3693: an orally bioavailable analog of the endogenous neuroactive steroid, pregnanolone, demonstrates potent sedative hypnotic actions in the rat. J Pharmacol Exp Ther 282:420 429

Gasior M, Carter RB, Goldberg SR, Witkin JM (1997) Anticonvulsant and behavioral effects of neuroactive steroids alone and in conjunction with diazepam. J Pharmacol Exp Ther 282:543-553

Gee KW, McCauley LD, Lan NC (1995) A putative receptor for neurosteroids on the $\mathrm{GABA}_{\mathrm{A}}$ receptor complex: the pharmacological properties and therapeutic potential of epalons. Crit Rev Neurobiol 9:207-227

Grant KA, Azarov A, Bowen CA, Mirkis S, Purdy RH (1996) Ethanol-like discriminative stimulus effects of the neurosteroid $3 \alpha, 21$-dihydroxy-5 $\beta$-pregnan-20-one in female Macaca fascicularis monkeys. Psychopharmacology 124:340-346

Grant KA, Azarov A, Shively CA, Purdy RH (1997) Discriminative stimulus effects of ethanol and 3 - $\alpha$-hydroxy-5- $\beta$-pregnan- 
20-one in relation to menstrual cycle phase in cynomolgus monkeys (Macaca fascicularis). Psychopharmacology 130: 59-68

Griffiths RR, Weerts EM (1997) Benzodiazepine self-administration in humans and laboratory animals - implications for problems of long-term use and abuse. Psychopharmacology 134:1-37

Griffiths RR, Lukas SE, Bradford D, Brady JV, Snell JD (1981) Self-injection of barbiturates and benzodiazepines in baboons. Psychopharmacology 75:101-109

Griffiths RR, Lamb RJ, Sannerud CA, Ator NA, Brady JV (1991) Self-injection of barbiturates, benzodiazepines and other sedative-anxiolytics in baboons. Psychopharmacology 103:154161

Heinsbroek RPW, van Haaren F, Zantvoord F, van de Poll, NE (1987) Discriminative stimulus properties of pentobarbital and progesterone in male and female rats. Pharmacol Biochem Behav 28:371-374

Holtzman SG (1990) Discriminative stimulus effects of drugs: Relationship to potential for abuse. In: Adler MW, Cowan A (eds) Testing and evaluation of drugs of abuse. Modern methods in pharmacology, vol 6. Wiley-Liss, New York, pp $193-210$
Johanson CE, Balster RL (1978) A summary of results of a drug self-administration study using substitution procedures in rhesus monkeys. Bull Narcot 30:43-54

Nader MA, Winger G, Woods JH, Woolverton WL (1991) Discriminative and reinforcing effects of brotizolam in rhesus monkeys. Psychopharmacology 103:166-171

Rowlett JK, Woolverton WL (1998) Discriminative stimulus effects of benzodiazepine agonists and partial agonists in pentobarbital-trained rhesus monkeys. Behav Pharmacol 9:81-92

Schuster CR, Thompson T (1969) Self-administration of and behavioral dependence on drugs. Annu Rev Pharmacol 9:483-502

Vanover KE (1997) Discriminative stimulus effects of the endogenous neuroactive steroid pregnanolone. Eur $\mathrm{J}$ Pharmacol 327:91-101

Wieland S, Belluzzi JD, Stein L, Lan NC (1995) Comparative behavioral characterization of the neuroactive steroids $3 \alpha-$ $\mathrm{OH}, 5 \alpha$-pregnan-20-one and $3 \alpha-\mathrm{OH}, 5 \beta$-pregnan-20-one in rodents. Psychopharmacology 118:65-71

Winger G, Herling S (1982) Discriminative stimulus effects of pentobarbital in rhesus monkeys: tests of stimulus generalization and duration of action. Psychopharmacology 76:172-176

Woods JH, Winger G (1995) Current benzodiazepine issues. Psychopharmacology 118:107-115 